\title{
Radiological Findings of Pneumonia In Neonates Hospitalized in A Tertiary Care Hospital
}

\author{
NAHID FARZANA ${ }^{1}$, MD. RUHULAMIN²
}

\begin{abstract}
:
Background: Pneumonia contributes to between 750,000 and 1.2 million neonatal deaths worldwide annually and neonatal pneumonia accounts for $10 \%$ of global child mortality. Chest radiography is the primary and most important imaging modality in the evaluation of neonatal pneumonia. The study was conducted to evaluate the common radiological findings of pneumonia among neonates to early diagnose the disease.

Methodology: This prospective observational study was conducted in Dhaka Shishu (children) Hospital from April to September 2014. A total of 50 neonates admitted in the inpatient department were included who fulfilled the inclusion criteria's like having difficult breathing, fast breathing $>60 / \mathrm{min}$, severe chest indrawing, grunting, cyanosis, cough or fever. Diagnosis was confirmed by Chest $X$-ray. Positive $X$-ray findings like lobar or segmental consolidation, nodular or coarse patchy parenchymal infiltrate, diffuse haziness or granularity, air bronchogram were included into the study. X-ray changes were assessed.
\end{abstract}

Results: Most commonly identified abnormality was patchy opacities (included nodular or coarse patchy opacities, diffuse haziness, air bronchogram), noted in 31(62.0\%) cases. Followed by homogenous opacities (consolidation) were found in 19(38.0\%) cases. Multifocal area involvement were found more $56.0 \%(28)$ than single area. On right side radiological changes commonly noted, especially right upper zone involvement was the commonest 30 (66.0\%). A comparison between severe and non- severe cases revealed that both types of opacities were found equally. But right sided Involvement was common in both groups.

Conclusion: Multifocal patchy opacities were the most common radiological finding in cases of neonatal pneumonia. Pneumonia lesions were more common in the right lung among neonates and common site was right upper zone.

Key words: Pneumonia, Neonate, Chest Radiograph

\section{Introduction}

Neonatal Pneumonia is the lung infection in a neonate. It is an inflammatory pulmonary process that may originate in the lung or be a focal complication of a systemic process ${ }^{1}$. Definition of pneumonia varies widely. Some requires the presence of infiltrates on a chest radiographs, others require only certain respiratory symptoms or signs ${ }^{2}$. Neonatal mortality rate is 24 per 1000 live births in Bangladesh ${ }^{3}$. Under

1. Resident Medical Officer, Department of Paediatric Cardiology, Dhaka Shishu Hospital

2. Ex. Professor \& Head, Department of Peaediatric Pulmonology and Respiratory Medicine, Dhaka Shishu Hospital

Correspondent: Dr. Nahid Faezana, Resident Medical Officer, Dhaka Shishu Hospital, Mob: 01612143924, Email:nahid.cmc41@yahoo.com Received: 15 April 2017
5 mortality in Bangladesh though came down from 90 to 42 , pneumonia incidence still remains very high ${ }^{3}$. It is estimated that 3.9 million of the 10.8 million deaths in children annually worldwide occur in the first 28days of life 4 . Neonatal pneumonia accounts for significant morbidity and mortality especially in developing countries like Bangladesh ${ }^{5}$. Pneumonia contributes to between 750,000 and 1.2 million neonatal deaths worldwide annually and neonatal pneumonia accounts for $10 \%$ of global child mortality 5 . Symptoms of pneumonia in neonates are mostly nonspecific. According to some study, common radiological findings found are : new infiltrate or effusion ${ }^{6}$. Recognized changes on chest radiographs included nodular or coarse patchy infiltrates, diffuse 
haziness or granularity on air bronchogram, perihilar interstitial streaking and lobar and sub-lobar consolidation ${ }^{7}$.

The sensitivity of clinical findings for radio logically diagnosed pneumonia in neonates has been evaluated in developing countries.

\section{Methodology}

This observational study was conducted in Dhaka Shishu Hospital from April 2014 to September 2014. This study included total 50 neonates with pneumonia who fulfilled the inclusion criteria admitted in the inpatient department of the hospital during this period. Inclusion criteria included 0 to 28 days old both term and preterm neonates having cough or fever, rapid or difficult breathing, respiratory rate $>60 / \mathrm{min}$, severe chest indrawing, grunting and /or cyanosis. Chest $X-$ ray findings included lobar or segmental consolidation, nodular or coarse patchy parenchymal infiltrate, diffuse haziness or granularity. After taking written consent from the patient's attendant, detail history was taken and physical examination was conducted. The history included name, age, sex, residence, birth weight, gestational age of neonate and symptoms included cough, difficulty in breathing, grunting, poor feeding. Physical examination findings included temperature, heart rate, respiratory rate, chest indrawing, cyanosis, capillary refill time (CRT). Chest radiograph were assessed by senior radiologist, pulmonologist and researcher herself. Patients were divided into two groups, a group with pneumonia having presentations of cyanosis and grunting and another group without these.

Chest $\mathrm{x}$-ray findings were compared in two groups. A structured questionnaire was used for recording all the information. Data were then analyzed and plotted in graphs and tables.

\section{Results}

In this study, a total of 50 neonates were enrolled who diagnosed as pneumonia clinically and confirmed by chest radiology.

Table -I

Chest $X$-ray findings in neonatal pneumonia cases $(n=50)$

\begin{tabular}{lcc}
\hline Chest x-ray findings & $\begin{array}{c}\text { Frequency } \\
\text { of cases }\end{array}$ & $\begin{array}{c}\text { Percentage } \\
(\%)\end{array}$ \\
\hline Patchy Opacities & 31 & 62.0 \\
Homogenous opacities & 19 & 38.0 \\
\hline
\end{tabular}

Radiological examination of pneumonia in neonates showed that patchy opacities (included nodular or coarse patchy opacities, diffuse haziness)were present in $31(62.0 \%)$ cases and homogenous opacity (consolidation) in $19(38.0 \%)$ cases (Table-I) .

Table-II

Sites of lesions in Chest $X$-rays of neonatal pneumonia cases $(n=50$

\begin{tabular}{lcc}
\hline $\begin{array}{l}\text { Radiological } \\
\text { findings }\end{array}$ & $\begin{array}{r}\text { No of Pneumonia } \\
\text { cases }(n=50)\end{array}$ & $\begin{array}{c}\text { Percentage } \\
(\%)\end{array}$ \\
\hline \multicolumn{2}{l}{ Sites of lesion (Involved zone) } \\
Right upper zone & 33 & 66.0 \\
Right mid zone & 28 & 56.0 \\
Right lower zone & 20 & 40.0 \\
Left upper zone & 10 & 20.0 \\
Left lower zone & 8 & 16.0 \\
Involvement of both lung & 6 & 12.0 \\
\hline
\end{tabular}

Radiological evidence of pneumonia among studied newborns showed the involvement of right upper zone in $33(66.0 \%)$ cases, right mid zone in $28(56.0 \%)$ cases, right lower zone in $20(40.0 \%)$ cases, left upper zone in $10(20.0 \%)$ cases, left lower zone in $8(16.0 \%)$ cases and both the lungs were involved in $6(12.0 \%)$ cases.

\section{Table-III}

Chest $X$-ray findings in two groups ( pneumonia with cyanosis \& grunting $(n=20)$ and pneumonia without cyanosis and grunting $n=30$ ).

\begin{tabular}{|c|c|c|}
\hline $\begin{array}{l}\text { Chest X-ray } \\
\text { findings }\end{array}$ & $\begin{array}{l}\text { Pneumonia with P } \\
\text { cyanosis and } \\
\text { grunting }(n=20)\end{array}$ & $\begin{array}{l}\text { neumonia without } \\
\text { cyanosis and } \\
\text { grunting }(n=30)\end{array}$ \\
\hline Patchy Opacities & $10(20.0 \%)$ & $18(36.0 \%)$ \\
\hline Homogenous opac & cities10 $(20.0 \%)$ & $12(24.0 \%)$ \\
\hline \multicolumn{3}{|l|}{ Number of lesions } \\
\hline \multicolumn{2}{|c|}{ Unifocal (single lesion)6(12.0\%) } & $11(22.0 \%)$ \\
\hline Multifocal (>2 sites & $14(28.0 \%)$ & $19(38.0 \%)$ \\
\hline \multicolumn{3}{|c|}{ Sites of lesion(Involved zone) } \\
\hline $\begin{array}{l}\text { Right side } \\
\text { Left side }\end{array}$ & $15(30.0 \%)$ & $25(50.0 \%)$ \\
\hline Both sides & $5(10.0 \%)$ & $5(10.0 \%)$ \\
\hline
\end{tabular}

Study showed that 20 neonates had cyanosis and grunting and rest of 30 patients had no cyanosis or grunting. Radiological findings among $1^{\text {st }}$ group 
showed patchy opacities found in $10(20.0 \%)$ cases and homogenous opacities in $10(20.0 \%)$ cases. Among them multifocal lesions were more 14 (28.0\%) and right side involvement were more $15(30.0 \%)$ prominent. Among $2^{\text {nd }}$ group radiological findings were like patchy opacities were more $18(36.0 \%)$ then homogenous opacities 12 (24.0\%). Multifocal lesions were more common in $19(38.0 \%)$ than unifocal lesion $11(22.0 \%)$ and right side involvement were more common in $25(50.0 \%)$ cases and both sides in 5 $(10.0 \%)$ cases.

\section{Discussion}

This study was conducted in Dhaka Shishu (children) Hospital from April 2014 to September 2014, included total 50 neonates having pneumonia to assess the pattern of chest radiographic findings. Among study cases, chest radiology showed patchy opacities was found more $31(62 \%)$ than homogenous opacities $19(38 \%)$. Benjamin et al described chest X-ray findings as diffuse reticular nodular appearance with focal or coarse densities which is comparable with this study ${ }^{8}$. The radiological findings among neonatal pneumonia cases observed by Mathur NB et al were alveolar infiltrate in $44.6 \%$ cases, sub-lobar consolidation in $17.4 \%$, lobar consolidation in $9.7 \%$, diffuse haziness in $11.6 \%$, and opacity with reticulogranular pattern in $1.9 \%$ and clear in $14.5 \%$ cases $^{7}$. In Bangladesh a study done at Dhaka showed that in case of neonate common chest X-ray findings were nodular coarse patchy opacities $(47.6 \%)$, diffuse haziness $(46.5 \%)$, sublobar consolidation $(2 \%)^{9}$. In another study neonates with congenital pneumonia presented with lobar or multilobar asymmetric consolidation found in $75.0 \%$ cases followed by bilateral, symmetrical and diffuse fine reticulogranular or reticulonodular infiltrates with normal lung volume in $25.0 \%$ neonates. ${ }^{10}$. In our study, multifocal area involvement were more common than single area. Study also found that right upper zone involvement was more than other zones such as right middle, lower, left upper and lower zone due to delayed clearance of fetal lung field. Bilateral opacities were observed only in $6(12.0 \%)$ cases. Falah et al described that the commonest radiographic appearances seen in neonatal pulmonary infection were bronchopneumonia (43.0\%) and right upper lobe consolidation $(34.0 \%)^{11}$. In one study there were diversity of radiographic changes in neonatal pneumonia, the most common abnormality identified was bilateral alveolar densities, found in $77.0 \%$ of patient. These were extensive and dense air with air bronchograms in $33.0 \%$ and less dense but bilateral and confluent in $24.0 \%$. Bilateral patchy, segmental densities were in $10 \%$ cases. Alveolar densities were predominantly right sided in $7.0 \%$, had a central perihilar distribution in $3 \%$ cases. Air bronchogram were noted in $50 \%$ cases ${ }^{12}$.

Study also found that $20(40.0 \%$.) neonate had serious presentations like cyanosis and grunting ( Table 3). Chest $x$-ray findings among these group showed half $10(20 \%)$ )of them had patchy opacities and half 10 (20\%)neonate had homogenous opacities. But in noncyanotic group, patchy opacities found in two third cases. Multifocal lesions were common than unifocal lesions and right sided involvement were found more in both cases.

\section{Conclusion}

Multifocal patchy opacities were the most common radiological finding in cases of neonatal pneumonia. Lesions were more common in the right lung among neonates and common sites of pneumonia were right upper zone followed by right middle zone, right lower zone and left upper zone. All babies presented with grunting and cyanosis had significant radiological findings .

\section{Limitations}

1. The study period was short

2. This study was conducted in a tertiary hospital where only referred neonates are admitted.

3. The sample size was calculated from previous hospital records which may not have reflected the actual number of neonates.

\section{References}

1. Stoll BJ, Kliegman RM. Respiratory tract disorder. In : Behrman RE, Klingman RM, Jenson $\mathrm{HB}$, editors. Nelson Textbook of Pediatrics, $17^{\text {th }}$ ed. Saunders, Philadelphia; 2004. P-573-88.

2. Duke T. Neonatal pneumonia in developing countries. Arch Dis Child Fetal Neonatal ed 2005; 90: F211-F219

3. Bangladesh health system review. 2015;5:2-145

4. Black RE, Morris SS, Bryce J. Where and why are 10 million children dying every year? Lancet 2003 ;361 : 2226-34.

5. The Child Health Research Project. Reducing perinatal and neonatal mortality : report of a meeting Baltimore, Maryland. Baltimore 1999; 3: 6-12. 
6. Stoll BJ. Infections of Neonatal infant. Behrman RE, Klingman RM, Stoll BJ editors. Nelson Textbook of Pediatrics, $19^{\text {th }}$ ed. Saunders, Elsevier, Philadelphia 2011. P-639.

7. Mathur NB, Garg K, Kumar S. Respiratory distress in neonates with special reference to pneumonia. Indian Pediatr 2002;39:529-37.

8. Benjamin Gaston. Pneumonia. Pediatrrev 2002; 23:133

9. MZ Islam, MM Hossain, M A M Mamun. Risk factors which affect the change of antibiotics in neonatal pneumonia observed in a tertiary care hospital. Journal of Northern International Med college 2009; 6: 21-24.

10. Temesgen T, Yohannes $\mathrm{H}, \mathrm{Z}$ Daniel .Patterns of Chest Radiographic Findings in Neonates with Respiratory Distress Admitted to the Neonatal Intensive Care Unit in TikurAnbesa Specialized Hospital. Malaysian Journal of Medical and Biological Research. 2014; 1:73-79

11. Falah D S, Read H A.Chest Radiographic Finding in Neonatal Dyspnea,Al-Kindy Col Med J 2008;4: 40-44

12. Philip H J, Mark B. Chen J S. Radiographic findings in neonatal pneumonia, AJR 1984;143:23-26. 